\title{
$\bullet$ \\ An in vitro Assessment of the Apical Sealing Ability of MTA Plus and Biodentin
}

\section{IJCRR \\ Section: Healthcare ISI Impact Factor (2019-20): 1.628 IC Value (2019): 90.81 $\operatorname{SJIF}(2020)=7.893$ \\ (c) (i) (3) Copyright@IJCRR}

\section{Revathi Bashyam¹, Ramesh Krishnan², Kruthika Murali ${ }^{3}$, Nandhini B. Selvarajan, Suresh Kumar Vasaviah5, Vinola Duraisamy ${ }^{6}$}

'Assistant Professor, Department of Pedodontics Trichy SRM Medical College Hospital and Research Centre, Trichy, Tamilnadu, India; ${ }^{2}$ Former Professor, Department of Pedodontics, Vinayaka Mission's Sankarachariyar Dental College, Vinayaka Mission's Research Foundation (Deemed to be University), Salem, Tamilnadu, India; 'Reader, Department of Pedodontics, Vinayaka Mission's Sankarachariyar Dental College, Vinayaka Mission's Research Foundation (Deemed to be University), Salem, Tamilnadu, India; ‘Senior Lecturer, Department of Pedodontics, Vinayaka Mission's Sankarachariyar Dental College, Vinayaka Mission's Research Foundation (Deemed to be University), Salem, Tamilnadu, India; 'HOD and professor, Department of Pedodontics, Vinayaka Mission's Sankarachariyar Dental College, Vinayaka Mission's Research Foundation (Deemed to be University), Salem, Tamilnadu, India; ${ }^{6}$ Professor, Department of Pedodontics, V Vinayaka Mission's Sankarachariyar Dental College, Vinayaka Mission's Research Foundation (Deemed to be University), Salem, Tamilnadu, India.

\section{ABSTRACT}

Introduction: The apical vessels may also be severed or damaged enough to interfere with the normal reparative process. Radicular lesions develop when microorganisms of sufficient pathogenicity and number gain access to peri-radicular tissues. Microorganisms may be predominantly resilient to eradication by host defence mechanisms and antimicrobial agents when they are arranging in an extraarticular biofilm.

Objectives: The present study aims to compare the apical sealing ability of two materials Mineral trioxide aggregate (MTA) plus and Biodentin as well as to evaluate bacterial microleakage using a bacterial leakage model for 28 days.

Methods: Sixty single-rooted extracted permanent teeth were selected. All the teeth should have straight pulp canals were included in the study while the tooth with root caries, multiple canals, lateral radicular canals Calcifications, peri-radicular resorptive changes excessive curvatures, developmental defects, root fractures, with internal resorption, previously endodontically treated cracks or root defects were excluded from the study. Samples used in this in-vitro study had been extracted for orthodontic or periodontal reasons.

Results: Biodentine and controls on day 1. There was no leakage observed for MTA plus and Biodentine. Only one sample of positive control leaked. The comparison was done using the Kruskal Wallis test and the p-value was found to be 0.392 which was statistically not significant. Biodentine and control groups on day 5 . On day $5,13.33 \%$ of MTA plus group leaked (2 out of 15 samples) against $40 \%$ of positive controls leaked (6out of 15 samples).

Conclusion: The resent study concludes that MTA plus and Biodentine have good apical sealing ability against E.faecalis at 28 days. Biodentine was better in performance than MTA plus in terms of apical sealing for accurately measuring the microleakage and quantify it further in-vitro models can be pursued.

Key Words: Apexogenesis, Microorganisms, Periradicular tissues, Pulpal hyperaemia, Pulpotomy

\section{INTRODUCTION}

Trauma to a tooth is invariably followed by pulpal hyperaemia, the extent of which cannot be always determined. Congestion and alteration in the blood flow in pulp initiate irreversible degenerative changes, which can result in pulpal necrosis. The apical vessels may also be severed or damaged enough to interfere with the normal reparative process. ${ }^{1}$ Radicular lesion develop when microorganisms of sufficient pathogenicity and number gain access to peri-radicular tissues. Once microorganisms are capable to assemble in an extraarticular biofilm, they may be predominantly resistant to removal by host defence mechanisms and antimicrobial agents. ${ }^{2}$ Due to the difficulty of the root canal organization and the trouble to clean it using the current techniques and instruments, root canals cannot always be sufficiently treated using a non-surgical orthograde approach. ${ }^{3}$ Periradicular surgery, when indicated should be considered an extension of

\section{Corresponding Author:}

Dr. Kruthika Murali, Reader, Department of Pedodontics, Vinayaka Mission's Sankarachariyar Dental College, Vinayaka Mission's Research Foundation (Deemed to be University), Salem, Tamilnadu, India.

ISSN: $2231-2196$ (Print)

Received: 12.10 .2020
ISSN: 0975-5241 (Online)

Revised: 16.11 .2020
Accepted: 18.12 .2020
Published: 10.03 .2021 
nonsurgical treatment as aetiology of the disease process and the objectives of the treatment are the same.

The prime purpose of a root-end filling material is to deliver an apical seal that avoids the movement of bacteria and the dispersion of bacterial contents from the root canal system into the periapical tissues. ${ }^{4}$ An ideal root-end filling material should adhere to the preparation walls, which is necessary to create a tight seal in the root canal system. ${ }^{5}$ It should be non-absorbable, radiopaque, easy to manipulate, dimensionally stable and can not be exaggerated by the occurrence of moisture. ${ }^{5}$

MTA is ideally suggested as a root-end filling material, but it has been used for pulpotomy, pulp capping procedures, apical barrier formation in teeth with open apexes, repair of root perforations, apexogenesis, and as a root canal filling material. The benefits of Pro root MTA as a root-end filling material, concerning the other stated alternatives, comprise superior sealing ability and improved marginal seal..$^{6-8}$ But it has certain clinical disadvantages such as it is tedious to handle and have a long setting time which could be overcome by MTA plus. But the material MTA plus is not much explored.

Biodentine (Septodont USA) was recently introduced to the dental market. This new bioactive cement has dentin - like mechanical properties and can be used as a repair material for root perforations, as a root-end filling material, and resorptions. Biodentine can be indicated in both the crown and root. So the present study aims to compare the apical sealing ability of two materials MTA plus and Biodentin as well as to evaluate bacterial microleakage using a bacterial leakage model for 28 days.

\section{MATERIALS AND METHODS}

The present study was conducted in the department of Pedodontics at Vinayaka missions Sankarachariyar Dental College Salem, Tamilnadu. 60 single-rooted extracted permanent teeth were selected. All the teeth should have straight pulp canals were included in the study while the tooth with root caries, multiple canals, lateral radicular canals Calcifications, peri-radicular resorptive changes excessive curvatures, developmental defects, root fractures, with internal resorption, previously endodontically treated cracks or root defects were excluded from the study. Samples used in this in-vitro study had been extracted for orthodontic or periodontal reasons. The study was approved by the institutional research committee and institutional ethical committee. The sample size was determined scientifically. Considering Alpha: 0.05, Power of the study: 0.8 and Effect size: 0.4. Therefore, the estimated sample size for the study was 15 for each group. This was calculated using the software G Power 3.1.
Grouping of samples was done by random allocation of prepared teeth was done.15 samples to each of the experimental group and control group.

\section{Group-1: Mineral trioxide aggregate (MTA) PLUS group $(\mathbf{n}=\mathbf{1 5})$}

MTA plus was manipulated as per the manufacturer's instructions and incrementally placed into the root end cavity and condensed well along the cavity walls and against a flattened file which was placed in the root canal. The initial set was allowed, after $48 \mathrm{hrs}$ the k-file was removed. Each tooth was placed in sterile gauze piece soaked in saline for $48 \mathrm{hrs}$ for initial hard setting.

\section{Group 2: Biodentine group ( $n=15)$}

Biodentine was mixed as per the manufacturer's instructions in an encapsulator and incrementally placed into the root end cavity and condensed well along the cavity walls and against a flattened file which was placed in the root canal. The initial set was allowed, after $24 \mathrm{hrs}$ the k-file was removed. Each tooth was placed in sterile gauze piece soaked in saline for $48 \mathrm{hrs}$ for the initial hard setting.

\section{Group 3: Positive control $(n=15)$}

Thermoplasticized gutta-percha (GP) was used without sealer to fill the root end cavity and condensed against the flattened $\mathrm{K}$ - file. The file was removed after $48 \mathrm{hrs}$ and placed in moist sterile gauze piece.

\section{Group 4: Negative control ( $n=15)$}

Root end preparations were filled with sticky wax and condensed against the k-file. After $48 \mathrm{hrs}$, the file was removed and placed in moist sterile gauze piece.

\section{Materials}

Materials used For control and experimental group were MTA plus (Prevest Denpro Ltd, Jammu, India), Biodentine (Septodont, Saint Maur des Fosses, France), Thermo plasticised Gutta-percha (Bee fill 2 in 1 obturation device, Germany), Sticky wax (Hiflex, UK). Materials used For canal preparation were ultrasonic diamond tips (Kis tips), 5.25\% sodium hypochlorite (Hyposol, Prevest Denpro), 17\% ethylenediaminetetraacetic acid (EDTA) (Dolo Endogel TM, Prevest Denpro). Materials used For bacterial leakage model were scintillation vials, orthodontic resin, cyanoacrylate, phenol lactose red broth (Sigma Aldrich), E.Faecalis in tryptone soya broth (TSB) agar to $1 \times 10^{9} \mathrm{CFU} / \mathrm{ml}$. Equipment used in the study were ethylene dioxide sterilization chamber

Statistical analysis was done using Kruskal-Wallis test and post-hoc-tuckey test to compare the intergroup difference and statistical significance was set at the level of $\mathrm{P}=0.05$. 


\section{RESULTS}

Table 1 indicates the Comparison among groups for apical bacterial leakage. Table 2 shows the recording of the number of samples leaked in each group and its percentage of failure from day one to 28 days.

Table 1: Comparison among groups for apical bacterial leakage

\begin{tabular}{|c|c|c|c|c|c|c|c|c|c|c|c|c|c|c|c|c|c|c|c|c|c|c|c|c|c|c|c|c|}
\hline \multirow{2}{*}{$\begin{array}{l}\text { days } \\
\text { Samples }\end{array}$} & \multicolumn{7}{|c|}{ POSITIVE CONTROL } & \multicolumn{7}{|c|}{ NEGATIVE CONTROL } & \multicolumn{7}{|c|}{ MTA PLUS } & \multicolumn{7}{|c|}{ BIODENTINE } \\
\hline & 1 & 2 & 5 & 7 & 8 & 14 & 28 & 1 & 2 & 5 & 7 & 8 & 14 & 28 & 1 & 2 & 5 & 7 & 8 & 14 & 28 & 1 & 2 & 5 & 7 & 8 & 14 & 28 \\
\hline 1 & $\times$ & $\times$ & $x$ & $\sqrt{ }$ & $\sqrt{ }$ & $\sqrt{ }$ & $\sqrt{ }$ & $x$ & $\times$ & $x$ & $x$ & $x$ & $x$ & $x$ & $\times$ & $x$ & $x$ & $x$ & $\times$ & $x$ & $\times$ & $x$ & $x$ & $x$ & $x$ & $x$ & $x$ & $\times$ \\
\hline 2 & $\times$ & $x$ & $x$ & $\sqrt{ }$ & $\sqrt{ }$ & $\sqrt{ }$ & $\sqrt{ }$ & $x$ & $\times$ & $x$ & $\times$ & $x$ & $x$ & $x$ & $x$ & $x$ & $x$ & $x$ & $\times$ & $x$ & $x$ & $x$ & $x$ & $x$ & $x$ & $\times$ & $x$ & $x$ \\
\hline 3 & $\sqrt{ }$ & $\sqrt{ }$ & $\sqrt{ }$ & $\sqrt{ }$ & $\sqrt{ }$ & $\sqrt{ }$ & $\sqrt{ }$ & $\times$ & $\times$ & $x$ & $x$ & $x$ & $x$ & $\times$ & $x$ & $\times$ & $\times$ & $x$ & $\times$ & $\times$ & $\times$ & $x$ & $x$ & $x$ & $\times$ & $\times$ & $\times$ & $\times$ \\
\hline 4 & $\times$ & $x$ & $\times$ & $\sqrt{ }$ & $\sqrt{ }$ & $\sqrt{ }$ & $\sqrt{ }$ & $\times$ & $x$ & $\times$ & $\times$ & $x$ & $\times$ & $\times$ & $x$ & $\times$ & $\times$ & $x$ & $\times$ & $\times$ & $\times$ & $x$ & $x$ & $x$ & $\times$ & $x$ & $x$ & $\times$ \\
\hline 5 & $\times$ & $\times$ & $\times$ & $\sqrt{ }$ & $\sqrt{ }$ & $\sqrt{ }$ & $\sqrt{ }$ & $x$ & $\times$ & $\times$ & $\times$ & $x$ & $\times$ & $\times$ & $\times$ & $\times$ & $\sqrt{ }$ & $\sqrt{ }$ & $\sqrt{ }$ & $\sqrt{ }$ & $\sqrt{ }$ & $x$ & $x$ & $x$ & $\times$ & $\times$ & $\times$ & $\times$ \\
\hline 6 & $\times$ & $\times$ & $x$ & $\sqrt{ }$ & $\sqrt{ }$ & $\sqrt{ }$ & $\sqrt{ }$ & $x$ & $\times$ & $\times$ & $x$ & $x$ & $\times$ & $\times$ & $x$ & $\times$ & $\times$ & $x$ & $\times$ & $x$ & $\times$ & $x$ & $x$ & $x$ & $x$ & $x$ & $\times$ & $\times$ \\
\hline 7 & $\times$ & $\sqrt{ }$ & $\sqrt{ }$ & $\sqrt{ }$ & $\sqrt{ }$ & $\sqrt{ }$ & $\sqrt{ }$ & $x$ & $x$ & $\lambda$ & $x$ & $x$ & $\times$ & $x$ & $x$ & $x$ & $\sqrt{ }$ & $\sqrt{ }$ & $\sqrt{ }$ & $\sqrt{ }$ & $\sqrt{ }$ & $\times$ & $x$ & $x$ & $\times$ & $\times$ & $x$ & $\times$ \\
\hline 8 & $\times$ & $x$ & $x$ & $\sqrt{ }$ & $\sqrt{ }$ & $\sqrt{ }$ & $\sqrt{ }$ & $\times$ & $x$ & $x$ & $\times$ & $x$ & $\times$ & $\times$ & $x$ & $\times$ & $\times$ & $x$ & $\times$ & $\times$ & $\times$ & $x$ & $x$ & $x$ & $\times$ & $x$ & $\times$ & $\times$ \\
\hline 9 & $\times$ & $\times$ & $\sqrt{ }$ & $\sqrt{ }$ & $\sqrt{ }$ & $\sqrt{ }$ & $\sqrt{ }$ & $\times$ & $x$ & 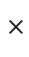 & $\times$ & $x$ & $\times$ & $\times$ & $x$ & $\times$ & $\times$ & $\sqrt{ }$ & $\sqrt{ }$ & $\sqrt{ }$ & $\sqrt{ }$ & $\times$ & $x$ & $x$ & $\sqrt{ }$ & $\sqrt{ }$ & $\sqrt{ }$ & $\sqrt{ }$ \\
\hline 10 & $\times$ & $\times$ & $\times$ & $\sqrt{ }$ & $\sqrt{ }$ & $\sqrt{ }$ & $\sqrt{ }$ & $x$ & $x$ & $x$ & $\times$ & $x$ & $\times$ & $\times$ & ^ & $\times$ & $\times$ & $\sqrt{ }$ & $\sqrt{ }$ & $\sqrt{ }$ & $\sqrt{ }$ & $x$ & $x$ & $x$ & $\sqrt{ }$ & $\sqrt{ }$ & $\sqrt{ }$ & $\sqrt{ }$ \\
\hline 11 & $\times$ & $x$ & $x$ & $\sqrt{ }$ & $\sqrt{ }$ & $\sqrt{ }$ & $\sqrt{ }$ & $x$ & $x$ & $x$ & $x$ & $x$ & $\times$ & $x$ & $x$ & $\times$ & $\times$ & $\sqrt{ }$ & $\sqrt{ }$ & $\sqrt{ }$ & $\sqrt{ }$ & $\times$ & $x$ & $x$ & $x$ & $\times$ & $\times$ & $\times$ \\
\hline 12 & $\times$ & $x$ & $\sqrt{ }$ & $\sqrt{ }$ & $\sqrt{ }$ & $\sqrt{ }$ & $\sqrt{ }$ & $x$ & $\times$ & $\times$ & $x$ & $x$ & $\times$ & $\times$ & $x$ & $\times$ & $\times$ & $\times$ & $\times$ & $x$ & $\times$ & $\times$ & $x$ & $x$ & $\sqrt{ }$ & $\sqrt{ }$ & $\sqrt{ }$ & $\sqrt{ }$ \\
\hline 13 & $\times$ & $\times$ & $\sqrt{ }$ & $\sqrt{ }$ & $\sqrt{ }$ & $\sqrt{ }$ & $\sqrt{ }$ & $\times$ & $x$ & $x$ & $\times$ & $x$ & $\times$ & $\sqrt{ }$ & $x$ & $\times$ & $\times$ & $\times$ & $x$ & $x$ & $\times$ & $\times$ & $x$ & $x$ & $\times$ & $\times$ & $x$ & $\times$ \\
\hline 14 & $\times$ & $x$ & $\sqrt{ }$ & $\sqrt{ }$ & $\sqrt{ }$ & $\sqrt{ }$ & $\sqrt{ }$ & $x$ & $x$ & $x$ & $x$ & $x$ & $\times$ & $x$ & $x$ & $\times$ & $\times$ & $\sqrt{ }$ & $\sqrt{ }$ & $\sqrt{ }$ & $\sqrt{ }$ & $x$ & $x$ & $x$ & $\times$ & $\times$ & $x$ & $\times$ \\
\hline 15 & $x$ & $x$ & $x$ & $\sqrt{ }$ & $\sqrt{ }$ & $\sqrt{ }$ & $\sqrt{ }$ & $x$ & $x$ & $x$ & $x$ & $x$ & $x$ & $x$ & $x$ & $x$ & $x$ & $x$ & $x$ & $x$ & $x$ & $x$ & $x$ & $x$ & $x$ & $x$ & $x$ & $x$ \\
\hline
\end{tabular}

$\sqrt{ }$ - samples with bacterial leakage

x-samples without bacterial leakage

Table 2: Distribution of apical bacterial leakage of samples in all the four groups in the percentage

\begin{tabular}{lcccccccc}
$\begin{array}{l}\text { Groups } \\
\text { Days }\end{array}$ & Positive & \multicolumn{2}{c}{ Negative } & \multicolumn{2}{c}{ MTA } & \multicolumn{2}{c}{ Biodefinite } \\
1 & No. of samples & $\%$ & No. of samples & $\%$ & No. of samples & $\%$ & No. of samples & $\%$ \\
2 & 1 & 6.67 & 0 & 0 & 0 & 0 & 0 & 0 \\
5 & 2 & 13.33 & 0 & 0 & 0 & 0 & 0 & 0 \\
7 & 6 & 40 & 0 & 0 & 2 & 13.33 & 0 & 0 \\
8 & 15 & 100 & 0 & 0 & 6 & 40 & 3 & 20 \\
14 & 15 & 100 & 0 & 0 & 6 & 40 & 3 & 20 \\
28 & 15 & 100 & 0 & 0 & 6 & 40 & 3 & 20 \\
\hline
\end{tabular}

Table 3: Comparison of apical bacterial leakage among MTA plus, Biodentine and controls (Day 1)

\begin{tabular}{lccccc} 
Group & $\begin{array}{c}\text { Apical } \\
\text { bacterial leakage }\end{array}$ & Percentage & Mean Rank & $\begin{array}{c}\text { Test Value (Kruskal } \\
\text { Wallis Test) }\end{array}$ & P Value \\
MTA Plus & 0 & 0 & 30.00 & & \\
Biodentine & 0 & 0 & 30.00 & 3.000 & 0.392 \\
Positive Control & 1 & 6.67 & 32.00 & \\
Negative Control & 0 & 0 & 30.00 & \\
\hline
\end{tabular}


Table 3 depicts the comparison of leakage of samples between MTA plus, Biodentine and controls on day 1. There was no leakage observed for MTA plus and Biodentine. Only one sample of positive control leaked. The comparison was done using the Kruskal Wallis test and the p-value was found to be 0.392 which was statistically not significant.

Table 4: Comparison of apical bacterial leakage among MTA plus, Biodentine and controls (Day 5)

\begin{tabular}{lcccc} 
Group & $\begin{array}{c}\text { Apical } \\
\text { bacterial leakage }\end{array}$ & Percentage & Mean Rank & $\begin{array}{c}\text { Test Value (Kruskal } \\
\text { Wallis Test) }\end{array}$ \\
MTA Plus & 2 & 13.33 & 30.50 & \\
Biodentine & 0 & 0 & 26.50 & 13.615 \\
Positive Control & 6 & 40 & 38.50 & $0.003^{*}$ \\
Negative Control & 0 & 0 & 26.50 & \\
\hline
\end{tabular}

Table 4 shows the intergroup comparison of leakage of samples between MTA plus, Biodentine and control groups on day 5. On day 5, 13.33\% of MTA plus group leaked (2 out of 15 samples) against $40 \%$ of positive controls leaked (6out of 15 samples). Statistical analysis was done using Kruskal Wallis test and p-value was found to be 0.003 which was statistically significant.

Table 5: Comparison of apical bacterial leakage among MTA plus, Biodentine and control groups on Days 7, 8 and 14

\begin{tabular}{lcccc} 
Group & $\begin{array}{c}\text { Apical } \\
\text { bacterial leakage }\end{array}$ & Percentage & Mean Rank & $\begin{array}{c}\text { Test Value (Kruskal } \\
\text { Wallis Test) }\end{array}$ \\
MTA Plus & 6 & 40 & 30.50 & \\
Biodentine & 3 & 20 & 24.50 & 34.417 \\
Positive Control & 15 & 100 & 48.50 & $0.001^{*}$ \\
Negative Control & 0 & 0 & 18.50 & \\
\hline
\end{tabular}

Table 5 illustrates the comparison of leakage of samples among MTA plus, Biodentine and control groups on day 7, 8 and 14. All the samples showed similar leakage on 7 th 8 th and $14^{\text {th }}$ day. The percentage of samples leaked for, MTA plus was $40 \%$ (6 out of 15 samples), whereas $20 \%$ of Biodentine showed leakage (3 out of 15 samples). When ob- served in control groups, $100 \%$ of positive controls leaked (15out of 15 samples); and negative control did not leak. Numerically, MTA plus samples leaked more than Biodentine group. Statistical analysis was done using the kruskal Wallis test and the p-value was found to be 0.000 which was statistically significant.

Table 6: Comparison of apical bacterial leakage among MTA plus, Biodentine and control groups (Day 28)

\begin{tabular}{lllll} 
Group & $\begin{array}{l}\text { Apical } \\
\text { bacterial leakage }\end{array}$ & Percentage & Mean Rank & $\begin{array}{l}\text { Test Value (Kruskal } \\
\text { Wallis Test) }\end{array}$ \\
MTA Plus & 6 & 40 & 30.00 & \\
Biodentine & 3 & 20 & 24.00 & 30.950 \\
Positive Control & 15 & 100 & 48.00 & $0.000^{*}$ \\
Negative Control & 1 & 6.67 & 20.00 & \\
\hline
\end{tabular}

Table 6 depicts the comparison of leakage of samples among MTA plus, Biodentine and control groups on day 28. When the percentage of apical leakage was assessed at $28^{\text {th }}$ day MTA plus samples showed $40 \%$, Biodentine showed $20 \%$, positive control showed $100 \%$ and negative control showed $6.67 \%$ of leakage, in which MTA plus showed more leakage than Biodentine. Statistical analysis showed a significant $\mathrm{p}$ value of 0.000 
Table 7: Inter group analysis using post hoc - Tukey test for days 7, 8 and 14

\begin{tabular}{|c|c|c|c|c|c|}
\hline & $\begin{array}{l}\text { Comparing } \\
\text { Group }\end{array}$ & Other Group & $\begin{array}{c}\text { Mean } \\
\text { Difference }\end{array}$ & $\begin{array}{l}\text { Std } \\
\text { Error }\end{array}$ & $\begin{array}{c}\mathbf{P} \\
\text { Value }\end{array}$ \\
\hline \multirow{12}{*}{ Day $7,8,14$} & \multirow[t]{3}{*}{ MTA Plus } & Positive Control & -0.600 & 0.120 & $0.000^{*}$ \\
\hline & & Negative Control & 0.400 & 0.120 & $0.008^{*}$ \\
\hline & & Biodentin & 0.200 & 0.120 & 0.347 \\
\hline & \multirow[t]{3}{*}{ Biodentin } & Positive Control & -0.800 & 0.120 & $0.000^{*}$ \\
\hline & & Negative Control & 0.200 & 0.120 & 0.347 \\
\hline & & MTA Plus & -0.200 & 0.120 & 0.347 \\
\hline & \multirow[t]{3}{*}{ Positive Control } & Negative Control & 1.000 & 0.120 & $0.000^{*}$ \\
\hline & & MTA Plus & 0.600 & 0.120 & $0.000^{*}$ \\
\hline & & Biodentin & 0.800 & 0.120 & $0.000^{*}$ \\
\hline & \multirow[t]{3}{*}{ Negative Control } & Positive Control & -1.000 & 0.120 & $0.000^{*}$ \\
\hline & & MTA Plus & -0.400 & 0.120 & $0.008^{*}$ \\
\hline & & Biodentin & -0.200 & 0.120 & 0.347 \\
\hline
\end{tabular}

Table 7 depicts the multiple comparisons among all the four groups. Multiple group comparison was done using post hoc-Tukey test. There was a statistically significant difference between the positive control and the MTA plus group and dentine group and also negative control. MTA plus group showed a significant difference with both the control groups. Biodentine group showed significant difference with positive control. Intergroup comparison between MTA plus and Biodentine group had a mean difference of 0.200 and with a standard error of 0.120 , the p-value was 0.347 , which was statistically insignificant.

Table 8: Inter group analysis using post hoc - Tukey test on $28^{\text {th }}$ day

\begin{tabular}{|c|c|c|c|c|c|}
\hline & $\begin{array}{l}\text { Comparing } \\
\text { Group }\end{array}$ & Other Group & $\begin{array}{c}\text { Mean } \\
\text { Difference }\end{array}$ & $\begin{array}{l}\text { Std } \\
\text { Error }\end{array}$ & $\begin{array}{c}\mathbf{P} \\
\text { Value }\end{array}$ \\
\hline \multirow[t]{12}{*}{ Day 28} & \multirow[t]{3}{*}{ MTA Plus } & Positive Control & -0.600 & 0.128 & $0.000^{*}$ \\
\hline & & Negative Control & 0.333 & 0.128 & 0.057 \\
\hline & & Biodentin & 0.200 & 0.128 & 0.411 \\
\hline & \multirow[t]{3}{*}{ Biodentin } & Positive Control & -0.800 & 0.128 & $0.000^{*}$ \\
\hline & & Negative Control & 0.133 & 0.128 & 0.728 \\
\hline & & MTA Plus & -0.200 & 0.128 & 0.411 \\
\hline & \multirow[t]{3}{*}{ Positive Control } & Negative Control & 0.933 & 0.128 & $0.000^{*}$ \\
\hline & & MTA Plus & 0.600 & 0.128 & $0.000^{*}$ \\
\hline & & Biodentin & .800 & .128 & $.000^{*}$ \\
\hline & \multirow[t]{3}{*}{ Negative Control } & Positive Control & -.933 & .128 & $.000^{*}$ \\
\hline & & MTA Plus & -.333 & .128 & .057 \\
\hline & & Biodentin & -.133 & .128 & .728 \\
\hline
\end{tabular}

Table 8 depicts the multiple comparisons among all the four groups. Multiple group comparison was done using post hoc-Tukey test. There was a statistically significant difference between the positive control and the MTA plus and the dentine group and also negative control. Intergroup comparison between MTA plus and Biodentine group had a mean difference of 0.200 and with a standard error of 0.128 , the p-value was 0.411 , which was statistically insignificant.

\section{DISCUSSION}

In the present study, two tricalcium silicate types of cement were compared in terms of apical sealing ability. Various approaches have been tried to assess apical microleakage. These include air pressure, neutron activation, radioisotope, electrochemical, fluid filtration, bacteria, and the use of the dyes. Numerous techniques are suggested to measure apical 
root canal leakage using transmission electron microscopy, scanning electron microscopy, and electron probe microscope analysis. There is no homogenous leakage test to estimate the sealing capacity of endodontic materials. ${ }^{9}$ Bacterial leakage model can be used to study the bacterial penetration across the material. A bacterial leakage model was chosen for the present study because it is most relevant in clinical perspective. ${ }^{10}$ Invitro study with bacterial leakage test was conducted for 28 days. The thickness of apical plugin this study is $3 \mathrm{~mm}$ as supported by Mehmet bani et al., ${ }^{11}$ The amount of apical microleakage was significantly lower for 3 and $4 \mathrm{~mm}$ apical plugs than 1 and $2 \mathrm{~mm}$ subgroups of Biodentine and MTA in his study. In the present study, the rood end cavity was prepared with ultrasonic diamond tips. Khandelwal et al., ${ }^{12}$ compared different retro preparations with MTA and Biodentine. Biodentine group prepared using ultrasonics for showed the best sealing than all the other tested groups. Regardless of the preparation techniques employed, Biodentine still presented good sealing than MTA. Preparation of the root end using ultrasonics showed less microleakage than bur prepared teeth for both filling materials. In this study, machine trituration done for biodetine as Gupta PK et al., ${ }^{13}$ reported more microleakage when Biodentine was manually manipulated. The setting time is one of the most clinically relevant factors to be considered. Hence in this study, all the samples were kept in moist gauze piece for a period of $48 \mathrm{hrs}$ to allow an initial setting time. Long-setting duration of cement reduces clinical problems since it maintains shape and support stresses during this period.

In the present study, MTA plus showed more apical bacterial leakage than Biodentine. In the negative control group only one sample leaked at the end of the study. The leakage in negative control can be attributed to nail varnish failure. Among the positive control group, there was a $100 \%$ apical bacterial leakage indicating the need for an ideal apical sealing material for the retrograde fillings. Under the experimental conditions of this study, dentine showed less leakage than MTA plus which was statistically insignificant. Biodentine and MTA plus showed significant difference than positive control which signifies that both the materials have the good apical sealing ability. The formation of CSH gel also reduces the porosity with time. The crystallization of the dentine continues up to 4 weeks, therefore, improving the strength as well as other mechanical properties (sealing ability). The high mechanical strength of Biodentine may be accredited to the removal of aluminates that reflects weakening and delicateness of the set material as described by the manufacturer. The thickness of the $\mathrm{Ca}$-and $\mathrm{Si}$-rich layers improved over time, and the thickness of the Ca-and Si-rich layer was meaningfully superior in Biodentine equated to MTA after 30 and 90 days, concluding that the dentine element uptake was superior for Biodentine than for MTA. ${ }^{14}$

The sealing capability of a material can be assessed by vari- ous criteria such as marginal adaptation, and porosity. When calcium silicate cement are mixed with water; several porosities and micro-channels are created which play a crucial role in the hydration reaction. Kokate and Pawar ${ }^{15}$ conducted a study that compared the microleakage of glass ionomer cement, MTA, and Biodentin when used as a retrograde filling material and concluded that Biodentin exhibited the least microleakage when compared to other materials used which supports the current study. ${ }^{16}$

Sulthan ${ }^{17}$ carried out a study to evaluate the $\mathrm{pH}$ and calcium ion release of MTA and Biodentin when used as root-end fillings. He determined that Biodentine showed alkaline $\mathrm{pH}$ and the ability to release calcium ions related to that of MTA. Blood contamination exaggerated the push-out bond strength of MTA Plus nevertheless of the setting time. ${ }^{18}$ Formosa et al., ${ }^{19}$ found that the anti-washout gel changed the rheology and properties of the material. In particular, it was noted that while MTA mixed with water had a sandy consistency, MTA mixed with anti-washout gel had a far more vicious and rubbery consistency and are most dough-like. This increased viscosity may explain from a purely physical standpoint, why MTA-AW developed the threshold strength of $3.92 \mathrm{MPa}$ sooner than MTA. The anti washout gel added to MTA did not affect the radiopacity of resultant material the observed an increase in compressive strength of MTAAW compared to MTA-W.

The present study has to be still explored with detail assessment of the leakage as it has certain experimental limitations invitro. It has certain limitations such as fewer sample size, limitation of in-vitro model, quantifiable evaluation etc. The study can be further directed invitro by extending the longevity of the study and quantifying the microleakage. The above statements, however, should be addressed in future experiments before any conclusive recommendations can be made.

\section{CONCLUSION}

The resent study concludes that MTA plus and Biodentine have lesser apical leakage and good apical sealing ability against E.faecalis at 28 days. Biodentine was better in performance than MTA plus in terms of apical sealing for accurately measuring the microleakage and quantify it further in vitro models can be pursued.

Conflict of interest: NIL

Source of funding: Self

\section{Authors contribution}

1. Dr. Revathi Bashyam - Data collection

2. Dr. Ramesh Krishnan - Investigation

3. Dr. Kruthika Murali- Investigation 
4. Dr. Nandhini.B.Selvarajan- Manuscript preperation

5. Dr. Suresh Kumar Vasaviah- Manuscript writing

6. Dr. Vinola Duraisamy- Editing, Fincial support

\section{REFERENCES}

1. McDonald RE, Avery DR, Dean JA. Management of trauma to the teeth and supporting tissues. 9th ed. St. Louis, Missouri: MOSBY. Dent Child Adoles 2011;404.

2. Siqueira JF, Jr, Lopes HP: Bacteria on the apical root surfaces of untreated teeth with peri-radicular lesions: a scanning electron microscopy study. Int Endod J 2001;34:216.

3. Torabinejad M, Watson TF, Pitt Ford TR. Sealing ability of a mineral trioxide aggregate when used as a root-end filling material. J Endod 1993;19:591-595.

4. Fogel HM and Peikoff MD. Microleakage of root-end filling materials. J Endon 2001;27(7):456-458.

5. Ingle JI, Bakland LK. Endodontics. 5th ed. Baltimore: BC Decker Inc.2002: 211-215.

6. Torabinejad M, Parirokh M. Mineral trioxide aggregate: a comprehensive literature review--part II: leakage and biocompatibility investigations. J Endod 2010;36(2):190-202.

7. Lee SJ, Monsef M, Torabinejad M. Sealing ability of a mineral trioxide aggregate for repair of lateral root perforations. J Endod 1993;19(11):541-544.

8. Torabinejad M, Hong CU, Pitt Ford TR, Kettering JD. Antibacterial effects of some root-end filling materials. J Endod 1995;21(8):403-406.

9. Iwami Y, Shimizu A, Hayashi M, Takeshige F, Ebisu S. Threedimensional evaluation of gap formation of cervical restorations. J Dent 2005;33:325-333.

10. Craig S. Hirschberg, Niyati S. Patel, Loken M. et al. Hartwell, Comparison of sealing ability of MTA and EndoSequence Bioceramic Root Repair Material: A bacterial leakage study. Quintessence Int 2013;44:e157-e162.
11. Bani M, Sungurtekin-Ekçi E, Odabaş ME. Efficacy of Biodentine as an Apical Plugin Nonvital Permanent Teeth with Open Apices: An In Vitro Study. BioMed Res Inter 2015;20(15):359362 .

12. Khandelwal A, Karthik J, Nadig RR, Jain A. Sealing ability of mineral trioxide aggregate and Biodentine as root-end filling material, using two different retro preparation techniques -An in vitro study. Int J Contemp Dent Med Rev 2015;15(11):511-513.

13. Gupta PK, Garg G, Kalita C, Saikia A, Srinivasa TS, et al. Evaluation of Sealing Ability of Biodentine as Retrograde Filling Material by Using two Different Manipulation Methods: An In Vitro Study. J Int Onc Heal 2015;7(7):111-114.

14. Khetarpal A, Chaudhary S, Talwar S, Verma M. Endodontic management of open apex using Biodentine as a novel apical matrix. Ind J Dent Res 2014;25:513-516

15. Kokate SR, Pawar AM. An in vitro comparative stereomicroscopic evaluation of marginal seal between MTA, glass ionomer cement \& biodentine as root-end filling materials using $1 \%$ methylene blue as the tracer. Endodontology 2012;24(2):36-42.

16. Bolhari B, Ashofteh Yazdi K, Sharifi F, Pirmoazen S. Comparative Scanning Electron Microscopic Study of the Marginal Adaptation of Four Root-End Filling Materials in Presence and Absence of Blood. J Dent 2015;12(3):226-234.

17. Sulthan IR, Ramchandran A, Deepalakshmi A, Kumarapan SK. Evaluation of $\mathrm{pH}$ and calcium ion release of mineral trioxide aggregate and a new root-end filling material. Eur J Dent 2012;2:166-169.

18. Aggarwal V, Singla M, Miglani S, Kohli S. Comparative evaluation of push-out bond strength of ProRoot MTA, Biodentine, and MTA Plus in furcation perforation repair. J Conserv Dent 2013;16:462-465.

19. Formosa LM, Mallia B, Camilleri J. A quantitative method for determining the anti washout characteristics of cement-based dental materials including mineral trioxide aggregate. Int Endod J 2013;46:179-186. 